\title{
Relation of progesterone and luteinizing hormone serum levels and Ultrasound endometrium criteria with intracytoplasmatic sperm injection outcome
}

\author{
Original \\ Article \\ Shahinaz, El-Shourbagy, Ayman El dorf \\ Department of Obstetrics \& Gynecology, Tanta University, Tanta, Egypt
}

\begin{abstract}
Background: Hormone levels (progesterone " $P$ " and luteinizing hormone "LH) are vitally important to the proper functioning of the female reproductive cycle and together with Ultrasound assessment of endometrial receptivity may predict success of in vitro fertilization/ intracytoplasmatic sperm injection (IVF/ICSI).

Objective: to study the effects of serum $P$ and LH levels together with Ultrasound assessment of endometrial receptivity at the day of human chorionic gonadotrophin administration on fertilization and pregnancy rates.

Patients and Methods: Thirty patients age ranged 22-38 years underwent ovarian stimulation using a gonadotrophinreleasing hormone $(\mathrm{GnRH})$ agonist for pituitary down-regulation, and then ovarian hyperstimulation was initiated with highly purified human menopausal gonadotrophin (HMG). Final oocyte maturation was triggered 36 hours after human chorionic gonadotrophin (hCG) injection. On the day of hCG administration (Day 0), serum progesterone, LH levels together with Ultrasound assessment of endometrial receptivity (thickness, morphology and the spiral artery resistance index "RI") were evaluated. Fertilization and pregnancy rates were recorded.

Results: There was no significant difference between the pregnant and non pregnant women, in respect to age. The pregnancy rate was not affected by the serum LH level but was only $18.75 \%$ in cycles in which serum $P$ was more than $1.2 \mathrm{ng} / \mathrm{ml}$ on day 0 , which was significantly lower than that in cycles in which serum $P$ was less than $1.2 \mathrm{ng} / \mathrm{ml}$ on day $0(64.28 \%)(P=0.001)$. The fertilization rate was lower in the cycles with higher levels of serum $P$ and/or LH than in cycles in which serum $P$ was less than $1.2 \mathrm{ng} / \mathrm{ml}$ and serum LH was normal (51.66 vs. 68.85\%). Failed cases had altered endometrium and a higher spiral artery RI (resistance index), meaning lower peri-implantation blood flow.

Conclusion: This study concluded that the progesterone levels on the day of hCG administration (Day 0) can affect the success of in vitro fertilization, as higher progesterone levels were associated with lower rates of pregnancy and fertilization. Increase serum $P$ level caused advanced endometrial maturation and impaired endometrial receptivity to embryo implantation. The embryo transfer (ET) in such cases can be canceled and freezing all embryos for future transfer must be considered, to increase acceptance of the endometrium and thus increase the success rate.
\end{abstract}

Key Words: day 0, gonadotrophin-releasing hormone, human chorionic gonadotrophin, in-vitro fertilization, luteinizing hormone, pregnancy rate, progesterone.

Revised: 25 September 2016, Accepted: 18 October 2016

Corresponding Author: Shahinaz El-Shourbagy, MD., Department of Obstetrics \& Gynecology, Tanta University, Egypt, Tel.: + 20100670 0410, E-mail: Shahyshorbagy70@yahoo.com

ISSN: 2090-7265, May 2017 , Vol. 7, No. 2

\section{INTRODUCTION}

Embryo quality and endometrial receptivity are the two parameters which determine the outcome of in vitro fertilization (IVF) ${ }^{(1)}$.

Uterine receptivity is influenced by hormonal changes during the cycle. Estrogen rises as the time of ovulation nears and causes a rise in LH that stimulates the release of the egg from the ovary. Progesterone levels rise following ovulation, preparing the uterus for implantation and pregnancy. It also inhibits the contraction of myometrium thus helping implantation of the embryo. If pregnancy occurs, HCG is produced which leads to continued progesterone production $^{(2)}$.

The effect of plasma progesterone $(P)$ on pregnancy rates in in vitro fertilization (IVF) is a controversial issue $\mathrm{e}^{(3)}$ 
Previously several researchers reported that high serum $P$ levels on the day of human chorionic gonadotropin administration are associated with a decrease in pregnancy rate $^{(3,4)}$. Conversely, other researchers have found no adverse effects of $P$ on pregnancy rate ${ }^{(5,6)}$. The influence of $P$ is related to adverse effects on endometrial receptivity or embryo quality ${ }^{(3,4)}$.

Several studies demonstrated a deleterious effect of high levels of $P$ on fertilization by increasing the tendency toward polyspermy. Furthermore, a higher fertilization rate was reported once $P$ level was $0.9 \mathrm{ng} / \mathrm{ml}^{(7,8)}$.

Successful implantation requires good harmony between the endometrium and blastocyst ${ }^{(9)}$. Ultrasound examination of the endometrium is a commonly used noninvasive tool to assess endometrial receptivity during IVF/ ICSI treatment. A good blood supply to the endometrium is an essential requirement for implantation and assessment of endometrial blood flow in IVF/ICSI treatment has attracted a lot of attention in recent years ${ }^{(10)}$.

Ultrasound parameters of endometrial receptivity include endometrial thickness, endometrial pattern, endometrial volume, and Doppler studies of endometrial vasculature $^{(11)}$. Endometrial vasculature has been shown to play a prominent role in the early endometrial response to the implanting blastocyst and vascular changes may contribute to the uterine receptivity ${ }^{(12)}$.

Tsai et al..$^{(13)}$ reported in terms of endometrial parameters, endometrial pattern has a significant effect on positive pregnancy and in all patients they studded however, thickness and vascularity do not change pregnancy results. Fanchin et al.14 supported this view and reported that hyperechogenic endometrium deteriorates IVF outcomes.

On the other hand Kevin et al. ${ }^{(15)}$ showed that clinical pregnancy and live-birth or ongoing pregnancy rates increase significantly with increasing endometrial thickness, independent of the effects of patient age and embryo quality.

The thickened endometrium provides a site for attachment, and is the source of nourishment for an implanting embryo during its first few weeks, until the placenta develops ${ }^{(16)}$.

We hypothesized that elevation in P levels at the time of oocyte aspiration would lead to deleterious effects on intracytoplasmatic sperm injection outcome. Thus, we designed the present study to assess such relationship between an elevated $P$ and ICSI outcome, through detecting the effects of serum $\mathrm{P}$ and $\mathrm{LH}$ levels together with Ultrasound measurement of endometrial receptivity at the day of human chorionic gonadotrophin administration on fertilization and pregnancy rates.

\section{PATIENTS AND METHODS}

The study was approved by the ethics committee of Obstetrics and Gynecology, Tanta University and informed consent was obtained from the patients for this study. We analyzed the results of 30 women with normal ovaries participating in an ICSI program-embryo transfer.

In the first stage down regulation was performed using gonadotrophin releasing hormone agonist (GnRH-a) and then ovarian hyperstimulation was initiated with administration of highly purified human menopausal gonadotrophin (HMG) on the 2nd day of the menstrual cycle.

When there were at least two leading follicles with a diameter of $>17 \mathrm{~mm}$, oocytes were retrieved by transvaginal ultrasound-guided follicular aspiration 3436hours after hCG injection. Number of oocytes retrieved, the cleavage rate, and the numbers of embryos obtained and their grades were evaluated before transfer based on the fragmentation pattern previously outlined by Alikani et $a l .{ }^{(15)}$. Embryos with good quality were transferred 72 $\mathrm{h}$ later.

Micronized vaginal progesterone was used for luteal support. Serum $\beta$-hCG levels were measured 14 days after embryo transfer (ET), and if positive, micronized vaginal progesterone was continued for 4 weeks.

Serum P and LH levels on the day of human chorionic gonadotropin (hCG) administration were measured. Numbers of mature oocyte after retrieval of the ovum and numbers of embryos obtained were evaluated.

Endometrial thickness and patterns assessed by grayscale ultrasound and endometrial vessel characteristics and Doppler velocimetry of the spiral arteries on the day of hCG administration were recorded.

Trans-vaginal sonography (TVS) was performed on the Xario (Toshiba, Tokyo, Japan) machine. The thickness of the endometrium was measured at the thickest part in the longitudinal plane. It was measured from the highly reflective interface of the junction of the endometrium and the myometrium. This measurement represented two layers of the endometrium ${ }^{(17)}$. In the presence of fluid in the endometrial canal, the two half thickness endometrial measurements were added together ${ }^{(18)}$.

Blood flow impedance of uterine spiral arteries was evaluated with the use of a computerized vaginal ultrasound with an integrated pulsed Doppler vaginal scanner (Xario, Tokyo, Japan) and assessed as RI, as reported elsewhere ${ }^{(19)}$. All women were grouped according to the success of ICSI and being pregnant in relation to hormonal assay (P\&LH level) and endometrial, receptivity. 


\section{STATISTICAL ANALYSIS}

Statistical analysis was carried out using the software program Statistical Package for the Social Sciences (SPSS) for Windows, version 13.0 (SPSS, Chicago). Quantitative data were presented as mean and standard deviation. Student's t-test was used to compare means of two independent groups based on levels of serum $\mathrm{P}$ and $\mathrm{LH}$ on the day of hCG administration. Result was considered significant at a $P$ value of $<0.05$.

\section{RESULTS}

The present study included 30 women having normal ovaries participating in an ICSI program-embryo transfer. All women were grouped according to the success of ICSI and being pregnant. The mean age of pregnant women was $29.16 \pm 3.76$ years, while the non pregnant women had mean age of $31.44 \pm 5$ years. There was no significant difference $(P=0.191)$ between them as regards the age (Table 1)

Table (II): shows pregnancy outcome in relation to Serum $P$ and LH levels on the day of human chorionic gonadotropin (hCG) administration, numbers of retrieved ova, numbers of MII oocyte and numbers of embryos obtained, endometrial thickness and mean spiral artery resis $\neg$ tance index (RI). Out of 30 cases twelve women get pregnant and showed pregnancy rate $40 \%$ and fertilization rate $61.16 \%$. Pregnant women had respectively low serum P level irrespective of serum LH level on day of hCG administration. There is highly significant difference between serum $P$ level in pregnant and non- pregnant women $(P=0.003)$ and also significant difference in number of MII oocyte and fertilized oocyte (embryo) $(\mathrm{P}=0.049-0.054$, respectively $)$.
There is no significant difference between serum LH level in pregnant and non- pregnant women $(P=0.698)$ and also in number of retrieved oocytes $(P=0.075)$. Regarding endometrial thickness and morphology, all cases who achieved pregnancies had thick endometrium and a tripleline pattern of the endometrium on day of hCG. There was no statistically significant difference in the Doppler indices of the spiral artery resis $\neg$ tance index (RI) between pregnant and non-pregnant women $(P=0.267)$.

Endometrial thickness was found to be strongly correlated with successful pregnancy in IVF/ICSI cycles. No pregnancies were achieved when endometrial thickness was less than $8 \mathrm{~mm}$ and the rate of pregnancy were recorded according to endometrial thickness (Table III).

Patients were divided into two groups according to the level of $P$ on day of hCG administration. Group A comprised 14 women (46.6\%) in which the $P$ level was $<1.2 \mathrm{ng} / \mathrm{ml}$ and group B comprised 16 women (54.4\%) in which the $P$ level was $>1.2 \mathrm{ng} / \mathrm{ml}$. Mean age was slightly lower in group A than in group B (29.6 years vs. 31.12 years, $P=0.367)$. Pregnancy rate was significantly lower in group B than in group A $(18.75 \%$ vs. $64.28, p=0.001)$. No pregnancy was achieved in our study with serum $P$ level $>2 \mathrm{ng} / \mathrm{ml}$ on the day of hCG administration. No significant difference was found between the two groups as regards the number of retrieved oocytes $(P=0.234)$, but significant differences were found between the two groups in the number of MII oocytes, fertilized oocytes and endometrial thickness. Concentrations of progesterone have no effect on spiral artery resis $\neg$ tance index (RI) but are effective on triple-line pattern (Table IV).

Table 1: Age in pregnant and non pregnant women.

\begin{tabular}{lcc}
\hline Age & Pregnant women & Non- pregnant women \\
\hline Range & $22-38$ years & $23-38$ years \\
& & $31.44 \pm 5$ \\
Mean + SD & $29.16 \pm 3.76$ & 0.191 \\
\hline
\end{tabular}


Table 2: Mean + standard deviation (SD) of serum P and LH level, No of retrieved (RT) ova, No of MII oocyte and No of embryo, endometrial thickness and morphology, spiral artery resis $\neg$ tance index (RI) in pregnant and non pregnant women.
Pregnant women
Non- pregnant women
$P$ value
(P versus Non $\mathrm{P})$

\begin{tabular}{|c|c|c|c|}
\hline Number (total 30) & $12(40 \%)$ & $18(60 \%)$ & \multirow[b]{2}{*}{$0.003 * *$} \\
\hline $\begin{array}{l}\text { Serum P } \\
\text { Range } \\
\text { Mean + SD }\end{array}$ & $\begin{array}{l}0.5-2 \mathrm{ng} / \mathrm{ml} \\
1.19 \pm 0.51\end{array}$ & $\begin{array}{l}0.82-4 \mathrm{ng} / \mathrm{ml} \\
2.24 \pm 0.95\end{array}$ & \\
\hline $\begin{array}{l}\text { Serum LH } \\
\text { Range } \\
\text { Mean + SD }\end{array}$ & $\begin{array}{c}1.6-5.5 \\
4.14 \pm 1.14\end{array}$ & $\begin{array}{c}1.3-13.2 \\
4.46 \pm 2.63\end{array}$ & \multirow[b]{2}{*}{0.075} \\
\hline $\begin{array}{l}\text { No of RT ova } \\
\text { Range } \\
\text { Mean }+ \text { SD }\end{array}$ & $\begin{array}{c}5-24 \\
13.08 \pm 6.43\end{array}$ & $\begin{array}{c}2-24 \\
8.94 \pm 5.70\end{array}$ & \\
\hline $\begin{array}{l}\text { No of MII oocyte } \\
\text { Range } \\
\text { Mean }+ \text { SD }\end{array}$ & $\begin{array}{c}2-18 \\
9.00 \pm 4.36\end{array}$ & $\begin{array}{c}1-12 \\
5.94 \pm 3.71\end{array}$ & $0.049 *$ \\
\hline $\begin{array}{l}\text { No of embryo } \\
\text { Range } \\
\text { Mean }+ \text { SD }\end{array}$ & $\begin{array}{c}2-16 \\
8.00 \pm 3.95\end{array}$ & $\begin{array}{c}1-12 \\
5.22 \pm 3.52\end{array}$ & $0.054^{*}$ \\
\hline $\begin{array}{l}\text { Fertilization rate } \\
\text { No of embryo/no of RT }\end{array}$ & $61.16 \%$ & $58.38 \%$ & \multirow{3}{*}{0.300} \\
\hline $\begin{array}{l}\text { Endometrial thickness (ED } \\
\text { TH) } \\
\text { Range } \\
\text { Mean + SD }\end{array}$ & $\begin{array}{c}8-14.6 \\
10.70 \pm 2.23\end{array}$ & $\begin{array}{c}4.4-16.8 \\
9.61 \pm 3.09\end{array}$ & \\
\hline $\begin{array}{l}\text { Endometrial } \\
\text { morphology(Triple line \%) }\end{array}$ & $12 / 12(100 \%)$ & $6 / 18(33.3 \%)$ & \\
\hline $\begin{array}{l}\text { RI (resis } \neg \text { tance index) } \\
\text { Range } \\
\text { Mean }+ \text { SD }\end{array}$ & $\begin{array}{c}0.78-1.3 \\
0.96 \pm 0.16\end{array}$ & $\begin{array}{c}0.68-1.4 \\
1.05 \pm 0.24\end{array}$ & 0.267 \\
\hline
\end{tabular}

$P>0.05=$ non-significant $P<0.05 *=$ significant- $P<0.001 * *=$ highly- significant

Table 3: Serum progesterone levels in correlation with cycle characteristics of the study groups (Mean + standard deviation or $\%)$..

\begin{tabular}{|c|c|c|c|}
\hline $\begin{array}{l}\text { Cycle characteristics } \\
(\mathrm{n}=30)\end{array}$ & $\begin{array}{c}\text { Group A } \\
(\mathrm{P}<1.2 \mathrm{ng} / \mathrm{ml}) \\
(\mathrm{n}=14)\end{array}$ & $\begin{array}{c}\text { Group A } \\
(\mathrm{P}>1.2 \mathrm{ng} / \mathrm{ml}) \\
(\mathrm{n}=16)\end{array}$ & $P$ value \\
\hline Age (years) & $29.60 \pm 4.06$ & $31.12 \pm 5.09$ & 0.367 \\
\hline Serum LH & $4.10 \pm 1.30$ & $4.53 \pm 2.70$ & 0.599 \\
\hline Pregnancy rate $(\%)$ & 9 out of $14(64.28 \%)$ & 3 out of $16(18.75 \%)$ & $0.001 * *$ \\
\hline No. of retrieved oocytes & $12.07 \pm 4.41$ & $9.31 \pm 7.40$ & 0.234 \\
\hline No. of MII oocytes & $9.21 \pm 3.64$ & $5.37 \pm 3.91$ & $0.010 *$ \\
\hline No. of embryo & $8.07 \pm 3.40$ & $4.81 \pm 3.72$ & $0.047 *$ \\
\hline $\begin{array}{l}\text { No embryo/ No RT oocytes } \\
\text { Fertilization rate }(\%)\end{array}$ & $\begin{array}{l}8.07 / 12.07 \\
66.85 \%\end{array}$ & $\begin{array}{l}4.8 / 9.3 \\
51.66 \%\end{array}$ & \multirow{3}{*}{$0.051 *$} \\
\hline $\begin{array}{l}\text { Endometrial thickness (ED } \\
\text { TH) } \\
\text { Range } \\
\text { Mean + SD }\end{array}$ & $\begin{array}{c}8-14.8 \\
11.10 \pm 2.49\end{array}$ & $\begin{array}{c}4.4-16.8 \\
9.12 \pm 2.78\end{array}$ & \\
\hline $\begin{array}{l}\text { Endometrial morphology } \\
\text { (Triple line \%) }\end{array}$ & $10 / 14(71.42 \%)$ & $8 / 16(50 \%)$ & \\
\hline $\begin{array}{l}\text { RI (resis } \neg \text { tance index) } \\
\text { Range } \\
\text { Mean }+ \text { SD }\end{array}$ & $\begin{array}{c}0.68-1.3 \\
0.96 \pm 0.18\end{array}$ & $\begin{array}{c}0.67-1.4 \\
1.06 \pm 0.23\end{array}$ & 0.233 \\
\hline
\end{tabular}

$P>0.05=$ non-significant $-P<0.05^{*}=$ significant $-P<0.001 * *=$ highly- significant 


\section{DISCUSSION}

Controlled ovarian hyperstimuation $(\mathrm{COH})$ protocols for in vitro fertilization or intracytoplasmic sperm injection are stressful, invasive and can be associated with adverse pregnancy outcome, including miscarriage and ectopic pregnancy. The early prediction of pregnancy outcome has therefore great importance for both couples and medical practitioners on IVF/ICSI units ${ }^{(20)}$.

In vitro fertilization-embryo transfer (IVF-ET) involves multiple follicular development, oocyte retrieval and embryo transfer after fertilization. Oocytes were fertilized in vitro by conventional IVF or ICSI, and ET occurred 3 days afterwards. All embryos transferred were 6 cells or greater and were of good quality $^{(2)}$

Successful implantation is dependent on close interaction between the embryo and endometrium ${ }^{(11)}$. Aflatoonian et al 21supported this view and reported that the success of IVF cycle was dependent on number and quality of oocytes and endometrial receptivity .

Endometrial receptivity is the window of time when the uterine environment is conductive to blastocyst acceptance and subsequent implantation ${ }^{(22)}$.

Elevated serum progesterone (EP) concentration is a potentially abnormal hormonal profile which has received much attention over the years. Originally thought to be a result of premature luteinisation ${ }^{(23)}$, EP can occur in the presence of low $\mathrm{LH}^{(24)}$, although reduced implantation can occur with the advancing of the endometrium by elevated circulating progesterone in the absence of a classical LH surge ${ }^{(25)}$. High serum $P$ adversely affects implantation and pregnancy rates $^{(22)}$

The present study include 30 women underwent ICSI, twelve of them $(40 \%)$ get pregnant with mean age of $29.16 \pm 3.76$ years, with no statistical difference between pregnant and non-pregnant women as regard age (mean age $31.44 \pm$ 5.years). Pregnant women in the present study had respectively low serum $P$ level irrespective of serum LH level on day of hCG administration ( $P$ level; $1.19 \pm 0.51$ vs. $2.24 \pm 0.95$ of non pregnant). Nine cases $(75 \%)$ had $P$ level $<1.2 \mathrm{ng} /$ $\mathrm{ml}$ and the other $3(25 \%)$ cases had $P$ level $>1.2 \mathrm{ng} / \mathrm{ml}$. There is highly significant difference between serum $P$ level in pregnant and non- pregnant women $(P=0.003)$. No pregnancy was achieved in our study with serum $P$ level $>2 \mathrm{ng} / \mathrm{ml}$ on the day of hCG administration.

Such finding coincided with Silverberg et $a l^{(26)}$ who showed that serum progesterone $(P 4)$ levels greater than $2.86 \mathrm{nmol} / \mathrm{L}(0.9 \mathrm{ng} / \mathrm{mL})$ on the day of
hCG administration are associated with decreased pregnancy rates in invitro fertilization/embryo transfer (IVF/ET) cycles. Their findings demonstrate that even modest increases in serum P4 levels (greater than 1.27 $\mathrm{nmol} / \mathrm{L}$ ) are associated with reduced pregnancy rates in IVF/ET cycles. Also, Kagawa et al ${ }^{(27)}$ showed that pregnancy rate was not affected by the serum LH level but was significantly lower in cycles where $P$ was 1.2 $\mathrm{ng} / \mathrm{ml}$ on day 0 , than that in cycles in which serum $P$ was less than $1.2 \mathrm{ng} / \mathrm{ml}$ on day 0 . Bergh et $a l^{(22)}$ found that high serum $P$ adversely affects implantation and pregnancy rates. Aflatoonian et $a l^{(21)}$ showed no significant differences in age (year) between women with low or increased serum progesterone on the day of human chorionic gonadotropin administration.

Several authors reported that outcome of IVF/ICSI has been inversely related to serum progesterone levels on the day of HCG administration ${ }^{(28,29)}$. Furthermore AZEM et $a l^{(30)}$ found an inverse relationship between $\mathrm{P}$ level and pregnancy rate. Later on, Nayak et $a l^{(2)}$ showed that elevated $\mathrm{P}$ on the day of oocyte retrieval is associated with significantly lower implantation and ongoing pregnancy rates.

In the present study the fertilization rate was significantly lower in the cycles with higher levels of serum $\mathrm{P}$ and/or LH than in cycles in which serum $P<1.2 \mathrm{ng} / \mathrm{ml}$ and serum $\mathrm{LH}$ was normal (51.66 vs. $66.85 \%$ ). This had been previously reported by Kagawa et al ${ }^{(27)}$ who showed lower fertilization rate in the cycles with higher levels of serum $\mathrm{P}$ than in cycles in which serum $\mathrm{P}$ was less than $1.2 \mathrm{ng} / \mathrm{ml}$ (50.5 vs. $78.8 \%)$.

Several studies have demonstrated a deleterious effect of $P$ on fertilization. Hartshorne 31 confirmed high polyspermic fertilization in oocytes retrieved from follicles with high $\mathrm{P}$ levels. Mio et $a l^{(7)}$ and Givens et $a l^{(8)}$ found a higher fertilization rate when $\mathrm{P}$ levels were $<1 \mathrm{ng} / \mathrm{ml}$ and $0.9 \mathrm{ng} / \mathrm{ml}$, respectively.

Regarding endometrial thickness and morphology, all cases who achieved pregnancies had thick endometrium and a triple-line pattern of the endometrium on day of hCG. There was no statistically significant difference in the Doppler indices of the spiral artery resis $\neg$ tance index (RI) between pregnant and non-pregnant women.

Endometrial receptivity is essential to implantation of an embryo and ultrasound has been developed as a valuable method in evaluation of endometrial preparation before embryo transfer in ICSI cases.

In our study, the endometrial thickness was found to be strongly correlated with successful pregnancy in ICSI cycles. The most suitable endometrial thickness 
for pregnancy was $8-10 \mathrm{~mm}(50 \%$ of them achieved pregnancy), followed by endometrial thickness of $10-12 \mathrm{~mm}$ ( $25 \%$ of them achieved pregnancy), then endometrial thickness of $12-14 \mathrm{~mm}(16.7 \%$ of them achieved pregnancy) and lastly the endometrial thickness $>14 \mathrm{~mm}$ ( $8.3 \%$ of them achieved pregnancy). In our study no pregnancies were achieved when endometrial thickness was less than $8 \mathrm{~mm}$. This clear relationship between endometrial thickness and pregnancy rate (PR) provides additional evidence to suggest that endometrial thickness is a useful indicator of endometrial, receptivity.

Our results agree with previous studies that reported a correlation between endometrial thickness and pregnancy rate $^{(32)}$. Singh et al $^{(33)}$ reported that, largest number of pregnancies occurred when the endometrial thickness is $8-10 \mathrm{~mm}$. He also, postulated that no pregnancies reported when endometrial thickness is less than $5.8 \mathrm{~mm}$. Weissman et $\mathrm{al}^{(34)}$ reported the lowest percentage of conception when endometrial thickness is more than $14 \mathrm{~mm}$.

In our research, all cases who achieved pregnancy had a triple-line pattern of the endometrium on day of hCG. Our results coincided with previous researchers who showed a correlation between the endometrium pattern and IVF success. Sher et al ${ }^{(35)}$ showed that the endometrial pattern has been correlated with IVF success rates, with a trilaminar pattern shown to be more favourable than a homogenous luteal pattern at the time of the human chorionic gonadotrophin administration. Singh et $a l^{(33)}$ showed that the triple -line pattern of the endometrium was good prognostic factor for the occurrence of pregnancy. Also, ElZenneni et al $^{(36)}$ stated that the triple layer endometrial pattern was the most suitable for conception.

The present study showed that concentrations of progesterone have slight effect on spiral artery resis $\neg$ tance index $(\mathrm{RI})$, where low RI $(0.96 \pm 0.16)$ was found in pregnant women or those who have $P<1.2$ $(0.96 \pm 0.18)$ than non pregnant women $(1.05 \pm 0.24)$ or those who have $P>1.2(1.06 \pm 0.23)$.

The measurement of impedance to uterine blood flow in IVF cycles has provided an indirect measure of endometrial receptivity ${ }^{(37,38)}$. Battaglia et al.39 reported the highest pregnancy rate in the group with lower resistance to blood flow in the uterine spi $\neg$ ral arteries. This finding revealing that the decrease in peripheral impedance in the uterine vasculature was considered to be a consequence of increased blood flow and a sign of high tissue perfusion, and this might be an important prerequisite for successful invitro fertilization and embryo transfer cycle ${ }^{(40)}$. With endometrial thickness less than $8 \mathrm{~mm}$ and no-tripleline pattern on hCG day in IVF/ICSI cycles, and high
RI there is a poor chance of achieving pregnancy. Average endometrial line thickness of 8-12 $\mathrm{mm}$ and triple line (good morphologic texture) are good prognostic values, together with the endometrial blood flow could be used as a predictor for success of implantation in IVF/ICSI cycles.

We suggest that in cases with increased progesterone level that cause advanced endometrial maturation and impaired endometrial receptivity. The embryo transfer (ET) in such cases can be canceled and considered freezing all embryos for future transfer, to increase acceptance of the endometrium and thus increase the success rate.

\section{CONFLICT OF INTEREST}

There are no conflicts.

\section{REFERENCES}

1. Yang JH, Wu MY, Chen CD, Jiang MC, Ho HN, Yang YS: Association of endometrial blood flow as determined by a modified colour Doppler technique with subsequent outcome of in-vitro fertilization. Hum Reprod, 1999; 14(6):1606- 1610.

2. Nayak S, Ochalski ME, Fu B, Wakim KM, Chu TJ, Dong X, Wakim AN: Progesterone level at oocyte retrieval predicts in vitro fertilization success in a short-antagonist protocol: a prospective cohort study. Fertil Steril, 2014; 101(3):676 -82.

3. Silverberg KM, Burns WN, Olive DL, Riehl RM, Schenken RS: Serum progesterone levels predict success of in vitro fertilization/embryo transfer in patients stimulated with leu-prolide acetate and human menopausal gonadotropins. J Clin Endocrinol Metab, 1991; 73:797-803.

4. Fanhin R, de Ziegler D, Taieb J, Hazout A, Frydman $\mathrm{R}$ : Premature elevation of plasma progesterone alters pregnancy rates of in vitro fertilization and embryo transfer. Fertil Steril, 1993;59:1090-1094.

5. Martinez F, Coroleu B, Clua E, Tur R, Buxaderas R, PareraN, Barri PN, Balasch J: Serum progesterone concentrations on the day of HCG administration cannot predict pregnancy in assisted reproduction cycles. Reprod Biomed, Online 2004; 8:183-190.

6. Venetis CA, Kolibianakis EM, Papanikolaou E, Bontis J, Devroey P, Tarlatzis BC: Is progesterone elevation on the day of human chorionic gonadotrophin administration associated with the probability of 
pregnancy in in vitro fertilization? A systematic review and meta-analysis. Hum Reprod Update, 2007; 13:343-355.

7. Mio Y, Sekijima A, Iwabe T, Onohara Y, Harada T, Terakawa N: Subtle rise in serum progesterone during the follicular phase as a predictor of the outcome of in vitro fertilization. Fertil Steril, 1992; 58:159-166.

8. Givens CR, Schriock ED, Dandekar PV, Martin MC: Elevated serum progesterone levels on the day of human chorionic gonadotropin administration do not predict out- come in assisted reproduction cycles. Fertil Steril, 1994;62:1011-1017.

9. Singh N, Bahadur A, Mittal S, Malhotra N, Bhatt A: Predictive value of endometrial thickness, pattern and sub-endometrial blood flows on the day of hCG by $2 \mathrm{D}$ doppler in in-vitro fertilization cycles: a prospective clinical study from a tertiary care unit. J Hum Reprod Sci, 2011;4:29-33.

10. Merce' LT, Barco MJ, Bau S, Troyano J: Are endometrial parameters by three-dimensional ultrasound and power Doppler angiography related to in-vitro fertilization/embryo transfer outcome? Fertil Steril, 2008;89:111-7.

11. Ernest Hung Yu NG and Pak Chung HO: Ultrasound Assessment of Endometrial Receptivity in in vitro Fertilization Treatment. Journal of Ultrasound in Obstetrics and Gynecotogy. April-June, 2010; 4(2): 179- 188.

12. Chien LW, Au HK, Chen PL, Xiao J, Tzeng CR: Assessment of uterine receptivity by the endometrial subendometrial blood flow distribution pattern in women undergoing in vitro fertilization-embryo transfer. Fertil Steril, 2002; 78(2):245- 251.

13. Tsai HD, Chang CC, Hsieh YY, Lee CC, Lo HY: Artificial insemination. Role of endometrial thickness and pattern, of vascular impedance of the spiral and uterine arteries, and of the dominant follicle. J Reprod Med, 2000; 3: 195- 200.

14. Fanchin R, Righini C, Ayoubi JM, Olivennes F, de Ziegler D, Frydman R: New look at endometrial echogenicity: objective computer-assisted measurements predict endometrial receptivity in in vitro fertilization-embryo transfer. Fertil Steril, 2000; 2: 274- 81 .

15. Kevin S. Richter, Ph.D.,a Kathleen R. Bugge, R.N.C.,a Jason G: Relationship between endometrial thickness and embryo implantation, based on 1,294 cycles of in vitro fertilization with transfer of two blastocyst-stage embryos. Fertility and Sterility, 2007; 87(1): 53- 59.
16. Richter KS, Bugge KR, Bromer JG, Levy M: Relationship between endometrial thickness and embryo implantation, based on 1294 cycles of in vitro fertilization with transfer of two blastocyst-stage embryos. Fertil Steril, 2007; 1: 53- 9.

17. Van Den Bosch T, Van Dendael A, Van Schoubroeck, D Wranz PAB, Lombard CJ: Combining vaginal ultrasonography and office endometrial sampling in the diagnosis of endometrial disease in postmenopausal women. Obstet Gynecol, 1995; 85:349- 52.

18. Levine D, Gosnik BB and Johnson LA: Change in endometrial thickness in postmenopausal women undergoing hormone replacement therapy. Radiology, $1995 ; 197: 603-608$.

19. Tamura H, Miwa I, Taniguchi K, Maekawa R, Asada $\mathrm{H}$, Taketani $\mathrm{T}$, : Different changes in resistance index between uterine artery and uterine radial artery during early pregnancy. Hum Reprod, 2008;23:285-9.

20. Ioannidis G, Sacks G, Reddy N, Seyani L, Margara R, Lavery S, Trew G: Day 14 maternal serum progesterone levels predict pregnancy outcome in IVF/ICSI treatment cycles: a prospective study. Human Reproduction, 2005; 20(3): 741-746.

21. Aflatoonian A, Davar1 R, Hojjat F: Elevated serum progesterone/ MII oocyte ratio on the day of human chorionic gonadotropin administration can predict impaired endometrial receptivity. Iran J Reprod Med, 2014 ; 12(6): 427- 434.

22. Bergh PA and Navot D: The impact of embryonic development and endometrial maturity on the timing of implantation. Fertil Steril, 1992; 58:537 -42.

23. Ubaldi F, Camus M, Smitz J, Bennink HC, Van Steirteghem A, Devroey P: Premature luteinization in in vitro fertilization cycles using gonadotropinreleasing hormone agonist (GnRH-a) and recombinant follicle-stimulating hormone (FSH) and $\mathrm{GnRH}-\mathrm{a}$ and urinary FSH. Fertil Steril, 1996; 66: 275 -80.

24. Werner MD, Forman EJ, Hong KH, Franasiak JM, Molinaro TA, Scott RT, Jr: Defining the "sweet spot" for administered luteinizing hormoneto- folliclestimulating hormone gonadotropin ratios during ovarian stimulation to protect against a clinically significant late follicular increase in progesterone: an analysis of 10,280 first in vitro fertilization cycles. Fertil Steril, 2014; 102: 1312- 7 .

25. Ubaldi F, Bourgain C, Tournaye H, Smitz J, Van Steirteghem A, Devroey P: Endometrial evaluation by aspiration biopsy on the day of oocyte retrieval in the embryo transfer cycles in patients with serum 
progesterone rise during the follicular phase. Fertil Steril, 1997; 67: 521- 526.

26. Silverberg KM, Burns WN, Olive DL, Riehl RM, Schenken RS:. Serum progesterone levels predict success of in vitro fertilization/embryo transfer in patients stimulated with leuprolide acetate and human menopausal gonadotropins. Clin Endocrinol Metab. 1991; 73 (4):797- 803

27. Kagawa T1, Yamano S, Nishida S, Murayama S, Aono T: Relationship among serum levels of luteinizing hormone, estradiol, and progesterone during follicle stimulation and results of in vitro fertilization and embryo transfer (IVF-ET). J Assist Reprod Genet. 1992; 9(2):106- 12.

28. Andersen AN, Devroey P, Arce JC: Clinical outcome following stimulation with highly purified $\mathrm{hMG}$ or recombinant FSH in patients undergoing IVF: a randomized assessor-blind controlled trial. Hum Reprod, 2006; 21: 3217- 3227.

29. Papanikolaou EG, Kolibianakis EM, Pozzobon C, Tank P, Tournaye H, Bourgain C, et al: Progesterone rise on the day of human chorionic gonadotropin administration impairs pregnancy outcome in day 3 single-embryo transfer, while has no effect on day 5 single blastocyst transfer. Fertil Steril, 2009; 91: 949 -952.

30. Azem F, Lessing JB, Malcov M, Yosef DB, Almog B, Amit A: Does high serum progesterone level on the day of human chorionic gonadotropin administration affect pregnancy rate after intracytoplasmic sperm injection and embryo transfer? Gynecol Endocrinol, 2008; 24(7): 368-372.

31. Hartshorne GM: Steroid production by the cumulus: relationship to fertilization in vitro. Hum Reprod 1989;4:742-745.

32. Zenke U and Chetkowski RJ: Transfer and uterine factors are the major recipient-related determinants of success with donor eggs. Fertil Steril, 2004;82:850-6.

33. Singh N, Bahadur A, Mittal S, Malhotra N, Bhatt A: Predictive value of endometrial thickness, pattern and sub-endometrial blood flows on the day of hCG by 2D doppler in in-vitro fertilization cycles: a prospective clinical study from a tertiary care unit. J Hum Reprod Sci, 2011;4:29-33.

34. Weissman A, Gotlieb L, Casper RF: The detrimental effect of increased endometrial thickness on implantation and pregnancy rates and outcome in an in vitro fertilization program. Fertil Steril 1999;71:147-9.

35. Sher G, Herbert C, Maasarani G, Jacobs MH: Assessment of the late proliferative phase endometrium by ultrasonography in patients undergoing IVF/ET Human Reproduction, 1991; 6: 232-237.

36. El-Zenneni H, Moustafa R, Abdel-Hafeez M,El-Salally $\mathrm{H}$, Abdel-Kader A, Elnaggar A, et al: Assessment of uterine, subendometrial blood flows and endometrial gland vascular endothelial growth factor (EG-VEGF) in women with unexplained infertility. Middle East Fertil, Soc J 2014

37. Steer CV, Campbell S, Tan SL, Crayford T, Mills C, Mason BA, et al: The use of transvaginal color flow imaging after invitro fertilization to iden $\neg$ tify optimum uterine conditions before embryo transfer. Fertil Steril, 1992; 57: 372- 6

38. Zaidi J, Campbell S, Pittrof R, Tan SL: Endometrial thickness, morphol $\neg$ ogy, vascular penetration and velocimetry in predicting implantation in an in vitro fertilization program. Ultrasound Obstet Gynecol, 1995; 6: $191-8$

39. Battaglia C, Larocca E, Lanzani A, Valentini M, Genazzani AR: Doppler ultrasound studies of the uterine arteries in spontaneous and IVF stimulated ovarian cycles. Gynecol Endocrinol, 1990; 4: 245- 50.

40. Uysal S, Özbay EPO, Ekinci T, Aksüt H, Karasu S, Iş1k AZ, SoyluF: Endometrial spiral artery Doppler parameters in unexplained infertility patients: is endometrial perfusion an important factor in the etiopathogenesis? J Turkish-German Gynecol Assoc, 2012; 13: 169- 71 